Original Research Paper

\title{
Pemberdayaan Masyarakat Dalam Rangka Penguatan Kelembagaan Masyarakat di Desa Menceh Kecamatan Sakra Timur Lombok Timur
}

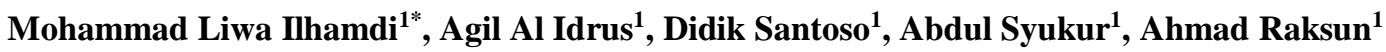

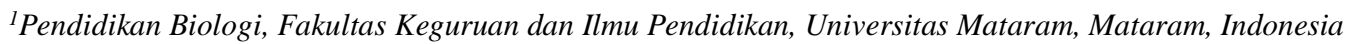

DOI: https://doi.org/10.29303/jpmpi.v4i2.833

Sitasi: Ilhamdi. M. L., Idrus, A. A., Santoso, D., Syukur, A., \& Raksun, A. (2021). Pemberdayaan Masyarakat Dalam Rangka Penguatan Kelembagaan Masyarakat di Desa Menceh Kecamatan Sakra Timur Lombok Timur. Jurnal Pengabdian Magister Pendidikan IPA, 4(2)

\section{Article history}

Received: 30 April 2021

Revised: 23 Mei 2021

Accepted: 30 Juni 2021

*Corresponding Author:

Mohammad Liwa Ilhamdi,

Pendidikan Biologi, Fakultas

Keguruan dan Ilmu Pendidikan,

Universitas Mataram, Mataram,

Indonesia;

Email:

liwa_ilhamdi@unram.ac.id

\begin{abstract}
Salah satu desa yang ada di Kecamatan Sakra Timur adalah desa Menceh. Desa ini termasuk desa yang belum maju sehingga banyak hal yang perlu ditingkatkan pelaksanaan kegiatan masyarakat, lembaga desa maupun pemerintah di tempat ini. Salah satu permasalahan adalah peran dan fungsi kelembagaan masyarakat belum optimal sehingga kegiatan masyarakat baik bidang sosial dan ekonomi belum optimal. Solusinya adalah perlu pemberdayaan masyarakat untuk penguatan kelembagaan masyarakat di desa Menceh. Metode yang digunakan adalah Focus Group Discussion (FGD), Pendampingan dan pemberian bantuan sembako. Hasil pengabdian sebagai berikut 1) telah dilakukan sosialisasi penguatan kelembagaan masyarakat Desa Menceh 2) peserta kegiatan pengabdian $100 \%$ mengikuti, menanggapi, berpartisipasi aktif dan memahami materi yang disampaikan tim pengabdian. Kesimpulan meningkatnya peran aktif masyarakat dalam rangka penguatan kelembagaan masyarakat desa Menceh Sakra Timur.
\end{abstract}

Keywords: Pemberdayaan; Kelembagaan; Desa Menceh.

yang kita miliki. Selain melalui pendidikan formal, baik pendidikan menengah maupun pendidikan tinggi, maka pengembangan SDM pada institusi pendidikan khusus seperti pesantren menjadi sangat penting. Agar barisan SDM yang dapat berperan dalam pembangunan desa menjadi bertambah banyak serta merata terutama dikalangan penduduk yang umumnya sangat miskin (Krisnawati , 2017)

Usaha-usaha pemerintah untuk membangun bangsa dengan menitik beratkan masyarakat desa sangat tepat. Namun memobilisasi masyarakat desa, bukanlah pekerjaan ringan dan mudah. Masyarakat desa yang sanggup berusaha sendiri, sanggup mencukupi kebutuhannya sendiri tidak dapat hanya digerakkan dengan aturan, perintah dan uang. Untuk waktu sesaat bisa saja berjalan, tetapi untuk jangka lebih jauh kelambanan-kelambanan akan terjadi. Dalam masyarakat desa, umumnya pengaruh kepemimpinan Kyai sebuah pesantren sangat amat besar. Sehingga peran kepemimpinan pengembangan SDM agar lebih berkualitas, sehingga diharapkan mampu mengambil peran aktif dalam memanfaatkan sumber daya alam (SDA) 
informal dalam menggerakkan usaha-usaha membangun masyarakat desa_sangat dibutuhkan.

Mendudukkan Lembaga Kemasyarakatan sesuai dengan tugas dan fungsinya. Lembaga Kemasyarakatan yang dibentuk di desa/kelurahan antara lain : Karang Taruna (Hadiprayitno, 2018). Selain itu ada juga Lembaga Pemberdayaan Masyarakat Desa/Kelurahan (LPMD/K); Lembaga Adat; Rukun Tetangga (RT); Rukun Warga (RW); Tim Penggerak Pemberdayaan Kesejahteraan Keluarga (TP PKK); dan Lembaga Kemasyarakatan lainnya (Sri Nugroho, 2018)

Sri Nugroho (2018) menyebutkan Salah satu faktor yang menentukan keberhasilan penguatan kelembagaan adalah adanya kemampuan dari sumber daya manusia dalam kelembagaan itu sendiri. Pengurus harus memenuhi syarat-syarat sebagai berikut : warga negara RI; Penduduk setempat; mempunyai kemampuan, kemauan dan kepedulian; bersedia dicalonkan menjadi pengurus. Selain persyaratan dalam rekrutmen pengurus guna meningkatkan kemampuan salah satu strategi dengan melaksanakan capacity building. Capacity building merupakan serangkaian strategi yang ditujukan untuk meningkatkan efisiensi dan responsivitas dari kinerja pemerintahan, dengan memusatkan perhatian kepada dimensi: (1)pengembangan sumber daya manusia; (2)penguatan organisasi; dan (3) penataan dan pemberdayaan kelembagaan (Krisnawati, 2017; Primadita, 2016; Anggraini, 2018).

Kegiatan Peningkatan Kapasitas Lembaga Kemasyarakatan dimaksudkan untuk mengoptimalkan peran dan fungsi lembaga sebagai mitra pemerintah desa/kelurahan dalam hubungan kerja yang harmonis. Kegiatan ini diarahkan pada: (i) pemantapan kelengkapan organisasi dan pengurus melalui Perdes/SK Kades/Lurah, (ii) peningkatan kapasitas manajemen lembaga, (iii) Peningkatan kemampuan pengelolaan administrasi lembaga.

Peningkatan kapasitas SDM Pengurus lembaga kemasyarakatan dilaksanakan untuk mengembangkan kemampuan teknis secara berjenjang dan berkelanjutan untuk mendukung terciptanya efektivitas dan responsivitas dari kinerja lembaga. Peningkatan kapasitas SDM dilaksanakan dalam bentuk; (1) Orientasi Tim Pembina Lembaga Kemasyarakatan, (2) Bimbingan Teknis Pemberdayaan Masyarakat bagi Perangkat Desa dan Pengurus Lembaga Kemasyarakatan, (3) bimbingan teknis penyusunan perencanaan pembangunan desa/kelurahan, (4) bimbingan teknis penyelenggaraan administrasi kelembagaan dan (5) bimbingan teknis dalam pelaksanaan pengawasan dan pertanggungjawaban pembangunan.

Peningkatan Kapasitas manajemen dilaksanakan melalui fasilitasi dalam perencanaan pembangunan dan bimbingan teknis dalam: (1) pengkajian potensi dan masalah serta penetapan prioritas pembangunan, (2) penyelenggaraan Musrenbang, (3) penyusunan rencana pembangunan jangka menengah (RPJM Desa) dan RKP, (4) pengelolaan pelaksanaan pembangunan, (5)pertanggungjawaban baik secara administratif maupun kepada publik terhadap pelaksanaan pembangunan, (6) pelestarian hasil pembangunan dalam bentuk pemanfaatan, pemeliharaan dan pengembangan. Proses Pendampingan Pemberdayaan dan penataan lembaga kemasyarakatan dilakukan melalui asistensi, pengorganisasian, pengarahan dan fasilitasi lembaga kemasyarakatan.

Tujuan kegiatan ini adalah pemberdayaan masyarakat dalam rangka penguatan kelembagaan masyarakat di Desa Menceh Kecamatan Sakra Timur dengan manfaat penguatan kelembagaan masyarakat di Desa Menceh Sakra Timur. Mengacu pada studi pendahuluan yang dilakukan menunjukkan bahwa kelembagaan masyarakat desa Menceh belum maksimal sehingga kegiatan ini penting dilakukan.

\section{Metode}

Metode Pelaksanaan yang diterapkan pada kegiatan pengabdian ini berupa pelatihan yang ditekankan dalam bentuk praktek langsung dan pembimbingan yang sifatnya mentoring. Pertama diberikan Kegiatan FGD diawali dengan memberikan informasi tentang pentingnya kelembagaan masyarakat. Peran dan fungsi kelembagaan, Partisipasi warga dalam mengoptimalkan fungsi dan kinerja kelembagaan masyarakat desa. Kemudian dilanjutkan dengan kegiatan pendampingan untuk penguatan kelembagaan masyarakat.

Adapun langkah-langkah kegiatan pelatihan yang akan dilakukan dapat dilihat pada gambar 1 . pada tahap persiapan dilakukan analisis kebutuhan penyusunan materi pelatihan koordinasi dengan pihak desa serta penyusunan jadwal pelaksanaan 
kegiatan. Tahap pelaksanaan akan diberikan informasi tentang kajian materi penguatan kelembagaan masyarakat. Tahap pembimbingan dan monitoring. Tahap evaluasi dan pelaporan akan dilakukan analisis untuk mengetahui ketercapaian dari tujuan kegiatan FGD.

\begin{tabular}{|c|c|c|c|}
\hline $\begin{array}{l}\text { TAHAP } \\
\text { Persiapan }\end{array}$ & $\begin{array}{c}\text { TAHAP } \\
\text { Pelaksanaan }\end{array}$ & $\begin{array}{c}\text { TAHAP } \\
\text { Pembimbingan } \\
\text { dan Pemantauan }\end{array}$ & $\begin{array}{c}\text { TAHAP } \\
\text { Evaluasi dan } \\
\text { Pelaporan }\end{array}$ \\
\hline Studi Literatur & \multirow{6}{*}{$\begin{array}{l}\text { Kajian tentang } \\
\text { informasi tentang } \\
\text { pentingnya } \\
\text { kelembagaan } \\
\text { masyarakat. Peran } \\
\text { dan fungsi } \\
\text { kelembagaan, } \\
\text { Partisipasi warga } \\
\text { dalam } \\
\text { mengoptimalkan } \\
\text { fungsi dan kinerja } \\
\text { kelembagaan } \\
\text { masyarakat desa. }\end{array}$} & \multirow{6}{*}{$\begin{array}{l}\text { Pembimbingan } \\
\text { dan pemantauan } \\
\text { peserta FGD di } \\
\text { Desa tentang } \\
\text { praktik penguatan } \\
\text { kelembagaan } \\
\text { masyarakat. }\end{array}$} & \multirow{6}{*}{$\begin{array}{l}\text { Penguatan } \\
\text { kelembagaan } \\
\text { masyarakat di } \\
\text { desa menceh } \\
\text { dapat } \\
\text { dilaksanakan } \\
\text { Penyusunan } \\
\text { Laporan } \\
\text { Pengabdian } \\
\text { kepada } \\
\text { masyarakat }\end{array}$} \\
\hline Need Analisis & & & \\
\hline Penyusunan Isi & & & \\
\hline Pelatihan & & & \\
\hline & & & \\
\hline $\begin{array}{l}\text { Penyusunan jadwal } \\
\text { Koordinasi dengan } \\
\text { Desa tentang } \\
\text { pelaksanaan } \\
\text { Pengabdian. }\end{array}$ & & & \\
\hline
\end{tabular}

Gambar 1 Tahapan pelaksanaan Kegiatan

\section{Hasil dan Pembahasan}

\section{a. Kegiatan Sosialisasi}

Sosialisasi dilakukan pada peserta kegiatan pengabdian yang terdiri dari 50 orang berasal dari kalangan masyarakat, tokoh agama, tokoh masyarakat dan aparat desa. Kegiatan sosialisasi dilakukan untuk memberikan penjelasan yang komprehensif kepada peserta tentang penguatan kelembagaan masyarakat desa oleh tim pengabdian. Kegiatan sosialisasi menjawab keraguan dan pertanyaan peserta kegiatan melalui aktivitas penyampaian materi, tanya jawab dan diskusi (Gambar 2).

Penjelasan yang mengedepankan pendekatan kemasyarakatan mengakibatkan pemahaman masyarakat dan aparat desa tentang penguatan kelembagaan masyarakat sangat baik.
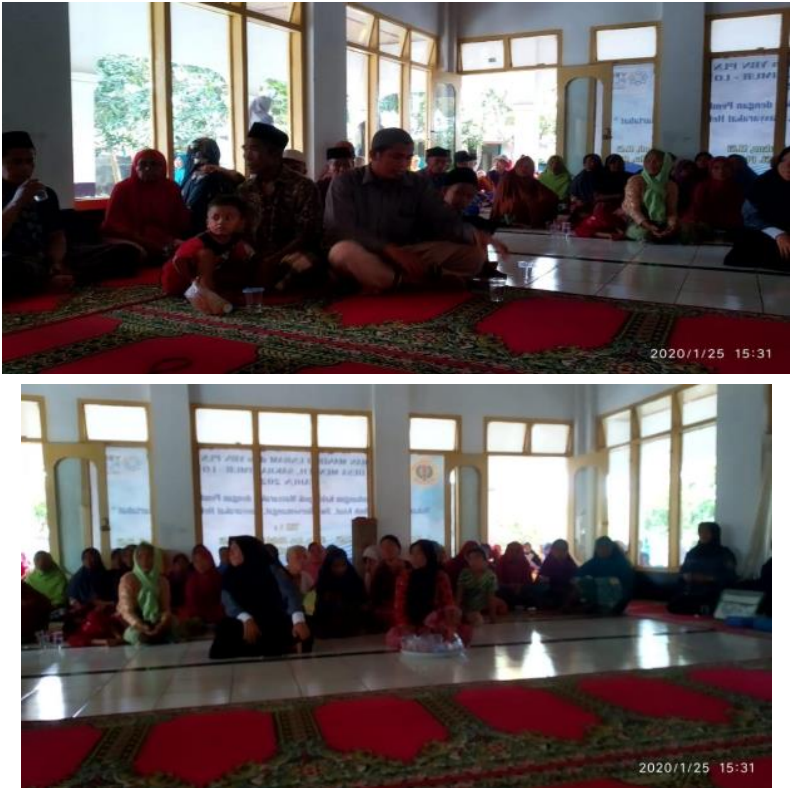

Gambar 2. Kegiatan Sosialisasi, Penjelasan Tim Pengabdian

\section{b. Kegiatan Diskusi dan Tanya Jawab}

Kegiatan diskusi dan tanya jawab dilakukan setelah ada sosialisasi dengan penjelasan tentang pengelolaan kelembagaan masyarakat desa. Peserta sangat antusias menanggapi, bertanya dan 
berdiskusi tentang topik ini karena peserta ingin sekali mengelola lembaga kemasyarakatan dengan baik sehingga lembaga ini berjalan sesuai tugas dan fungsinya. Jika kelembagaan masyarakat sudah kuat maka efeknya ke peningkatan kesejahteraan masyarakat desa secara keseluruhan.

Pertanyaan terkait penguatan kelembagaan masyarakat ini menarik karena banyaknya pertanyaan yang muncul yang mengarah ke semangat untuk meningkatkan peranan kelembagaan masyarakat untuk melaksanakan kegiatannya menjadi lebih baik dan sukses.

\section{c. Pemberian Bantuan}

Pemberian bantuan dilakukan untuk merangsang kegiatan kelembagaan masyarakat Desa Menceh menjadi lebih bersemangat dalam menjalankan tugas kelembagaan (Gambar 3).

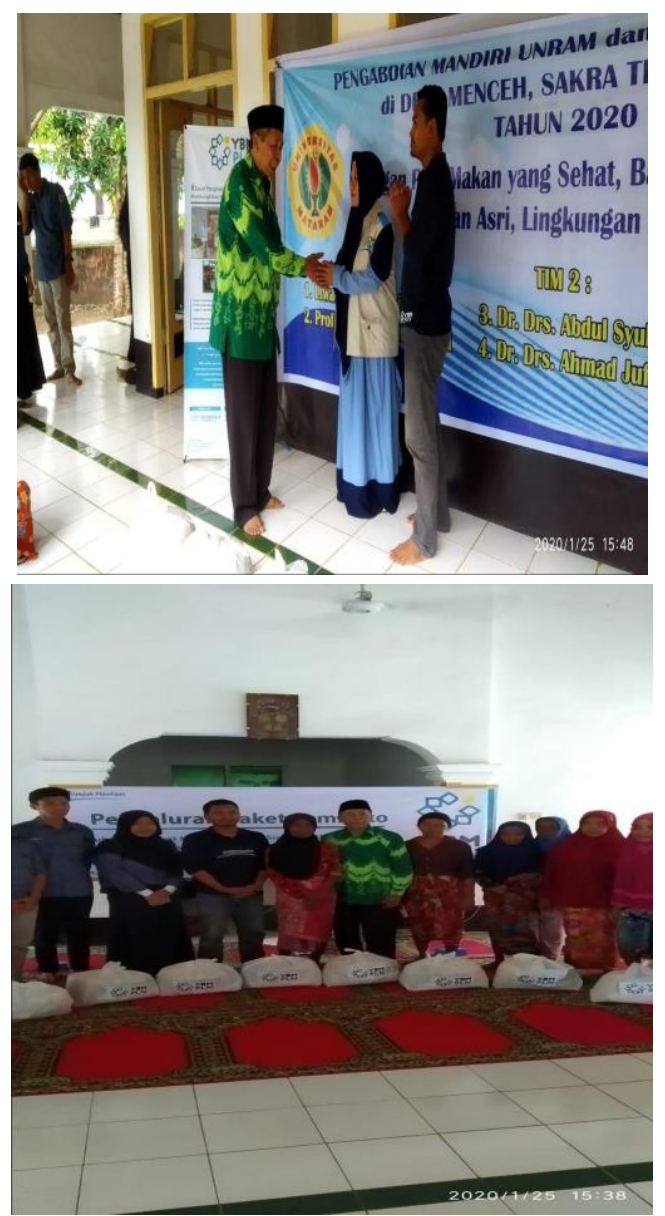

Gambar 3. Pemberian bantuan untuk penguatan kelembagaan masyarakat.

\section{Kesimpulan}

Kesimpulan dari kegiatan ini adalah:

1. Seluruh peserta kegiatan pengabdian pemberdayaan masyarakat dalam rangka penguatan kelembagaan masyarakat di Desa Menceh Kecamatan Sakra Timur sangat antusias.

2. Materi sosialisasi $100 \%$ peserta mengikuti dan memahami isi kegiatan pengabdian.

Meningkatnya peran aktif masyarakat dalam rangka penguatan kelembagaan masyarakat desa Menceh Sakra Timur.

\section{Ucapan Terima Kasih}

Ucapan terima kasih pula disampaikan kepada pihak LPPM Universitas Mataram atas fasilitasi kegiatan pengabdian serta antusiasme peserta selama pengabdian kepada masyarakat berlangsung.

\section{Daftar Pustaka}

Anggraini Oktaviani. 2018. Penguatan modal sosial berbasis kelembagaan lokal Masyarakat pesisir perspektif gender Di kabupaten Bantul, Jurnal JSEP Vol 11 (2): 11-24

Erna Setijaningrum, 2017, Penguatan aspek sistem: Pengembangan lembaga pemberdayaan masyarakat desa Sebagai upaya pengentasan penduduk rentan miskin, Jurnal Cakrawala Vol. 11 No. 2 Desember 2017: 137 - 144

Hadiprayitno G. Ilhamdi ML, Al Idrus A. Mertha G. 2018, Sosialisasi Peran dan Fungsi Mangrove Pada Masyarakat di Kawasan Gili Sulat Lombok Timur, Jurnal Pengabdian Magister Pendidikan IPA Vo.1 (1)

Krisnawati Cici, 2017, Penataan lembaga kemasyarakatan desa di kecamatan tambang tahun 2010 - 2015, JOM FISIP Vol. 4 (1): 1-14

Primadhita Yuridistya, 2016. Penguatan Lembaga Pemberdayaan Ekonomi Perempuan Melalui Koperasi (Studi Kasus Koperasi Simpan Pinjam Perempuan Suara Ibu 
Peduli Cilandak, Jakarta Selatan) Jurnal Pengembangan Wiraswasta Vol. 18 (2) :189-198

Sri Nugroho Hananto, 2018, Menimbang Pentingnya Penguatan Kelembagaan Pemerintahan Desa, Journal of Governance, Volume 3 (1: 35-49 